\title{
Motor activity of the sigmoid colon in chronic constipation: comparative study with normal subjects
}

\author{
P. MEUNIER ${ }^{1}$, ANNIE ROCHAS, AND R. LAMBERT
}

From the Manometric Investigation Laboratory, Hôpital Debrousse, Laboratory of Physiology, Faculty of Medicine Lyon Nord, and the Department of Gastroenterology, Hopital Edouard Herriot, Lyon, France

SUMMARY Manometric studies of the sigmoid colon were performed on 17 healthy volunteers and on 49 constipated patients, after a long period of fasting (18-20 hours). Motility was recorded using perfused catheters at basal level during 45 minutes, then 30 minutes after a $0.5 \mathrm{mg}$ intravenous injection of neostigmine, and, finally, 30 minutes during and after a meal. Motor activity was assessed by a motility index (per cent of activity $\times$ mean amplitude of waves). In both normal and constipated patients, the basal motility index was very low (respectively $82 \pm 16$ and $110 \pm 113$ ). This low level of activity was due to the long fasting period imposed on all the subjects. After neostigmine the motility index increased in both controls $(347 \pm 256)$ and constipated patients $(311 \pm 323)$; this test, however was found to be unreliable. The meal increased the motility index to significantly higher values than after neostigmine in controls $(538 \pm 215)$. In constipated patients the mean meal motility index was comparable with that of controls $(577 \pm 549)$ with a large distribution of individual values. Using the mean meal motility index \pm 2 SD of the control group as a term of comparison, the patients were segregated into three groups: 'hypomotor' patients (eight cases), 'normomotor' patients (33 cases), and 'hypermotor' patients (eight cases). From the evidence of this series of clinically well-defined constipated patients, it was concluded that only the meal test is able to segregate three significant patterns of sigmoid activity and that a large number $(68 \%)$ of constipated patients exhibit normal sigmoid motor activity.

\begin{abstract}
Abnormal motor activity of the sigmoid colon has been described in various disorders, including the irritable colon syndrome, diverticulosis of the colon, diarrhoeal states, and constipation (Connel, 1962; Wangel and Deller, 1965; Waller et al., 1972; Kirwan and Smith, 1977). It has been shown that, in constipation, the colonic motor disorder consists mainly in over-segmentation: regardless of the underlying disorder, an over-active sigmoid colon inhibits the transit of stools (Chowdury et al., 1976). However, in previous studies of colonic motility (Meunier et al., 1978), it was observed that such over-segmentation was not always present in chronic constipation. The present study is an attempt further to investigate sigmoid motor abnormalities in chronic constipation. On the other

\footnotetext{
Address for correspondence and reprints requests: Dr P. Meunier, Laboratoire D'Exploration Fonctionnelle, Manométrique Urinaire et Digestive, Hôpital Debrousse, 69322 Lyon, Cédex 1, France.

Received for publication 13 June 1979
}

hand, as the motor responses to neostigmine and meal are the more commonly used colonic motility tests, our aim was to compare the usefulness of these two tests as investigative tools for colonic motor disorders.

\section{Methods}

\section{SUBJECTS}

Sigmoid motility studies were performed on 17 healthy volunteers (control subjects) and on 49 chronically constipated patients. Details concerning the control subjects and constipated patients are presented in Table 1.

The control subjects were selected from medical students with no history of gastrointestinal disease and with normal bowel habits and consistencythat is, they passed at least one normal stool every two days. Informed and written consent was obtained from all of these subjects. 
Table 1 Number, sex, and age of control subjects and constipated patients

\begin{tabular}{lrrrllll}
\hline & \multicolumn{3}{c}{ Sex } & & \multicolumn{2}{l}{ Age $(y r)$} \\
\cline { 6 - 7 } \cline { 6 - 7 } & No. & $M$ & \multicolumn{1}{c}{$F$} & & Mean & Range \\
\hline Control subjects & 17 & 14 & 3 & & $22 \pm 3 \cdot 2$ & $19-33$ \\
Constipated patients & 49 & 9 & 40 & & $40 \pm 12 \cdot 9$ & $15-72$ \\
\hline
\end{tabular}

The common clinical history of the constipated patients was that of a prolonged period of abnormal and infrequent stools. Without treatment, stool frequency of these patients was less than one every three days, but, in all cases, frequency of stools depended upon the laxative and/or the enema used. Stool consistency varied, likewise, with the drugs used. In most cases, constipation first occurred during childhood or adolescence, and had always lasted for longer than five years. In all patients, constipation was unsuccessfully treated with various and multiple laxatives. However, the barium enema study and rectosigmoidoscopy of those patients chosen were required to be normal-that is, without signs of laxative disease. All patients were thoroughly investigated to excludeany gastrointestinal, metabolic, or drug-induced cause for the alteration in bowel habits, and constipation was the only complaint of these patients. The clinical and manometric investigations were performed while the patients were in hospital to avoid the risk of self-medication by the patients.

\section{Methods}

Motility recordings were performed after an 18-20 hour fast. A cleansing enema (Normacol), was administered four to six hours before each study. A triple lumen PVC catheter with side-openings spaced at $8 \mathrm{~cm}$ intervals was introduced through a sig- moidoscope, so that the distal, middle, and proximal side-openings were approximateively at 26,18 , and $10 \mathrm{~cm}$ respectively from the anal margin. The total length of the catheter was $50 \mathrm{~cm}$; each lumen had an internal diameter of $3.3 \mathrm{~mm}$, and the side-openings were 3 to $4 \mathrm{~mm}$ in length. By means of a constant infusion pump (type 871012, Braun, Melsungen, Federal Republic of Germany), the three lumens were perfused with water (flow rate $=0.13 \mathrm{ml}$. $\min ^{-1}$ ). Each lumen was connected to a pressure transducer (type P $23 \mathrm{~V}$, Statham Laboratories, Cambridge, MA, USA), the output of which was amplified and recorded on a multichannel galvanometer recorder (type RT8, Sefram, Paris, France). During this study, patients rested in the left supine position; they were allowed to read, but sleeping and smoking were prohibited.

\section{STUDY DESIGN}

The procedure included three steps. First, basal motility was recorded during 45 minutes. Then, 30 minutes of motility were recorded after an injection of neostigmine (Prostigmine, $0.5 \mathrm{mg}$, intravenously). After the recovery of a basal level of activity, a third period of activity ( 30 minutes) was recorded during and after a meal. This meal, not standardised, consisted of a cold plate (mainly salad), a hot plate (meat and vegetables), some cheese, and a piece of fruit. The calorific value of such a meal varied between 3750 and $4600 \mathrm{~kJ}$-that is, approximately 900 to $1100 \mathrm{kCal}$. As during previous studies (unpublished data) we had observed a better sigmoid response to rapidly eaten meals than to slowly eaten meals, subjects were instructed to eat rapidly. The total duration of this meal was never allowed to exceed 15 minutes.

In order to observe if a fasting period of 18-20 hours had any effect on sigmoid motility, the basal motility study (45 minutes) was repeated in five of

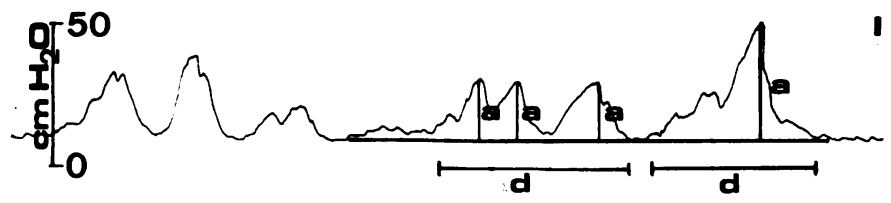

Fig. 1 Sample tracing of sigmoid pressure 10 sec

11 I is the measurement at $26 \mathrm{~cm}$ from the anal margin, II and III were recorded respectively at 18 and $10 \mathrm{~cm}$ from the anal margin. a: amplitude of each wave. $d$ : duration of motor activity. Scale is identical for the three recordings. 
Table 2 Mean results $( \pm 1 S D)$ and ranges of values observed in control subjects

\begin{tabular}{|c|c|c|c|c|c|c|}
\hline & \multicolumn{2}{|c|}{ Percentage of activity } & \multicolumn{2}{|c|}{$\begin{array}{l}\text { Waves' amplitude } \\
\left(\mathrm{cm} \mathrm{H}_{2} \mathrm{O}\right)\end{array}$} & \multicolumn{2}{|c|}{ Motility index } \\
\hline & Mean & Range & Mean & Range & Mean & Range \\
\hline $\begin{array}{l}\text { Basal level } \\
\text { Neostigmine response } \\
\text { Meal response }\end{array}$ & $\begin{array}{r}8 \pm 1 \cdot 5 \\
22 \pm 13 \cdot 7 \\
33 \pm 8.9\end{array}$ & $\begin{array}{r}0-17 \\
6-43 \\
22-48\end{array}$ & $\begin{array}{r}9 \pm 1 \cdot 1 \\
16 \pm 6 \cdot 9 \\
16 \pm 5 \cdot 6\end{array}$ & $\begin{array}{r}0-17 \\
9-30 \\
10-26\end{array}$ & $\begin{array}{r}82 \pm 16 \\
347 \pm 256 \\
538 \pm 215\end{array}$ & $\begin{array}{c}0-210 \\
96-1032 \\
220-989\end{array}$ \\
\hline
\end{tabular}

the control subjects (four males, one female) after a fast of only three to five hours.

\section{QUANTITATIVE STUDY ANALYSIS}

For the purpose of this study, only recordings obtained from the catheter opening at $26 \mathrm{~cm}$ from the anal margin were analysed. For each period of activity (basal, neostigmine response, and meal response), sigmoid motor activity was quantified by determining the mean amplitude of waves, the percentage of activity (sum of waves' duration $\times 100 /$ total duration of the period of recording), and the motility index, which is, according to Weinrich and Andersen (1976), the product of the mean amplitude of waves and the percentage of activity. The motility index is, therefore, the most significant parameter, as it includes the two components of motility-that is, the amplitude and the duration of waves. Waves of $5 \mathrm{~cm} \mathrm{H}_{2} \mathrm{O}$ or less were excluded from these calculations.

To avoid divergences of interpretation between different investigators, all calculations were carried out by only one of the authors (P. M.).

A sample recording is presented in Fig. 1. On this tracing it is shown how the motility parameters were derived from the actual recording.

Results are expressed as the mean \pm 1 SD. Normal range for each of the three parameters (mean amplitude, percentage of activity, and motility index) for the three recording periods (basal, neostigmine response, and meal response) was considered to be the mean \pm 2 SD of the values found for the control subjects. Statistical analysis was performed using Student's $t$ test.

\section{Results}

CONTROL SUBJECTS

Results for the four motility parameters during the three periods of activity are presented in Table 2 .

When the mean values found at the basal level were compared with those found after stimulation by neostigmine and the meal, it was seen that both neostigmine and the meal significantly increased the percentage of activity $(\mathrm{P}<0.01$ with neostigmine and $P<0.001$ with the meal), the mean amplitude of the waves $(P<0.01$ with neostigmine and the meal), and the motility index $(\mathrm{P}<0.001$ with neostigmine and the meal).

Comparison of the mean results for the neostig-

Table 3 Comparison of basal motility values found in five controls after fasting period of 18 -20 hours and of three to five hours

\begin{tabular}{|c|c|c|c|c|c|c|c|c|}
\hline \multirow[b]{2}{*}{ Sabjects } & \multirow[b]{2}{*}{ Sex } & \multirow[b]{2}{*}{$\begin{array}{l}\text { Age } \\
(y r)\end{array}$} & \multicolumn{3}{|c|}{ After 18-20 hours' fast } & \multicolumn{3}{|c|}{ After 3-5 hours' fast } \\
\hline & & & $\begin{array}{l}\text { Percentage } \\
\text { of activity }\end{array}$ & $\begin{array}{l}\text { Waves' } \\
\text { amplitude } \\
\left(\mathrm{cm} \mathrm{H}_{2} \mathrm{O}\right)\end{array}$ & $\begin{array}{l}\text { Motility } \\
\text { index }\end{array}$ & $\begin{array}{l}\text { Percentage } \\
\text { of activity }\end{array}$ & $\begin{array}{l}\text { Waves' } \\
\text { amplitude } \\
\left(\mathrm{cm} \mathrm{H}_{2} \mathrm{O}\right)\end{array}$ & $\begin{array}{l}\text { Motility } \\
\text { index }\end{array}$ \\
\hline $\begin{array}{l}1 \\
2 \\
3 \\
4 \\
5 \\
\text { Mean } \pm S D\end{array}$ & $\begin{array}{l}\mathbf{M} \\
\mathbf{M} \\
\mathbf{M} \\
\mathbf{F} \\
\mathbf{M}\end{array}$ & $\begin{array}{l}20 \\
21 \\
19 \\
22 \\
20\end{array}$ & $\begin{array}{l}11 \\
21 \\
5 \\
5 \\
10 \\
10 \pm 6.5\end{array}$ & $\begin{array}{r}13 \\
10 \\
8 \\
9 \\
11 \\
10 \pm 1.9\end{array}$ & $\begin{array}{l}143 \\
210 \\
40 \\
45 \\
110 \\
110 \pm 71 \cdot 1\end{array}$ & $\begin{array}{l}20 \\
22 \\
11 \\
19 \\
23 \\
19 \pm 4 \cdot 7\end{array}$ & $\begin{array}{l}16 \\
24 \\
14 \\
18 \\
11 \\
17 \pm 4 \cdot 9\end{array}$ & $\begin{array}{l}320 \\
528 \\
154 \\
342 \\
253 \\
319 \pm 137 \cdot 7\end{array}$ \\
\hline
\end{tabular}

Table 4 Mean results $( \pm 1 S D)$ and ranges of values observed in constipated patients

\begin{tabular}{|c|c|c|c|c|c|c|}
\hline & \multicolumn{2}{|c|}{ Percentage of activity } & \multicolumn{2}{|c|}{ Waves' amplitude } & \multicolumn{2}{|c|}{ Motility index } \\
\hline & Mean & Range & $\begin{array}{l}\left(\mathrm{cm} \mathrm{H} \mathrm{H}_{2} \mathrm{O}\right) \\
\text { Mean }\end{array}$ & Range & Mean & Range \\
\hline $\begin{array}{l}\text { Basal level } \\
\text { Neostigmine response } \\
\text { Meal response }\end{array}$ & $\begin{array}{l}11 \pm 10 \cdot 3 \\
21 \pm 18 \cdot 5 \\
50 \pm 20 \cdot 1\end{array}$ & $\begin{array}{l}0-37 \\
0-94 \\
2-81\end{array}$ & $\begin{array}{r}9 \pm 4 \cdot 7 \\
12 \pm 6 \cdot 5 \\
12 \pm 6 \cdot 5\end{array}$ & $\begin{array}{l}0-17 \\
0-31 \\
6-49\end{array}$ & $\begin{array}{l}110 \pm 113 \\
311 \pm 323 \\
577 \pm 549\end{array}$ & $\begin{array}{r}0-510 \\
0-1541 \\
13-2646\end{array}$ \\
\hline
\end{tabular}


mine response and the meal response showed that the mean amplitude of the waves was not significantly different. However, the meal response was significantly better than the neostigmine response in the cases of the percentage of activity and the motility index $(P<0.05)$. Furthermore, the standard deviation for each of the three parameters (mean amplitude, percentage of activity, and motility

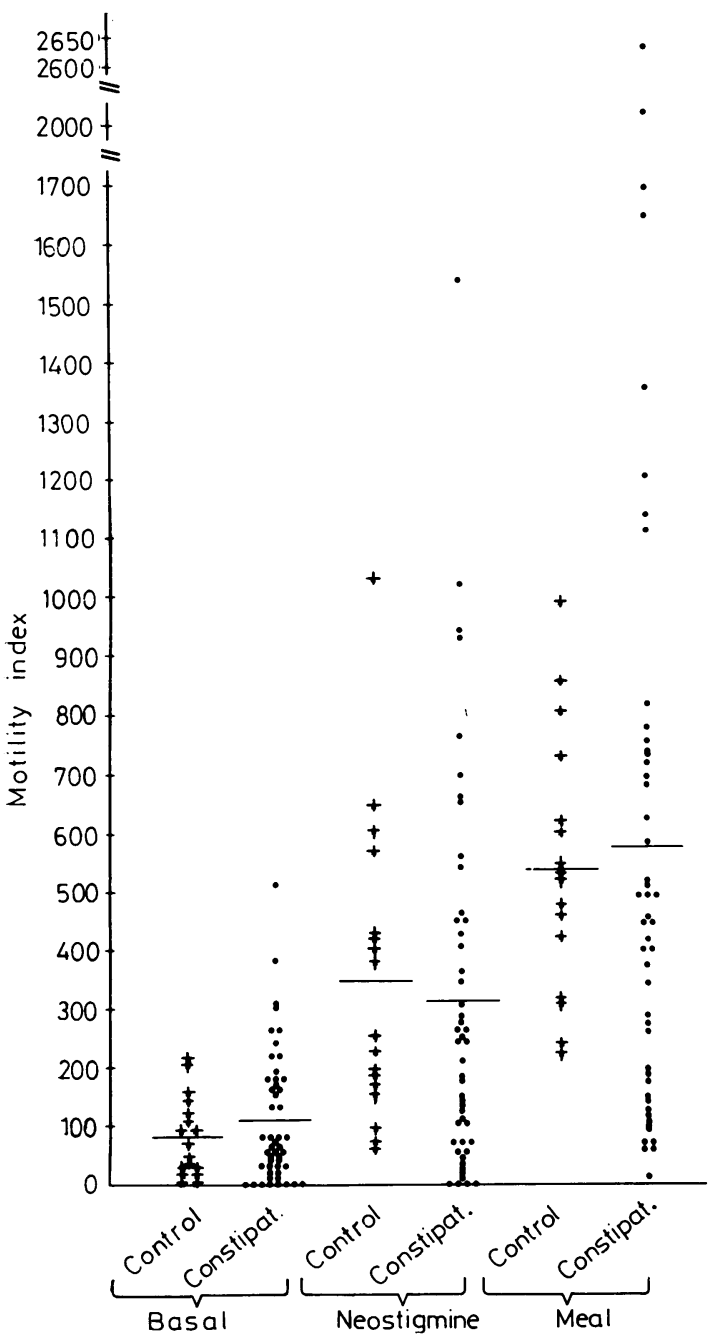

Fig. 2. Comparison of the individual motility index values found in control $(+)$ and in constipated (O) patients during the three recording periods. The mean values are indicated by the black bars. Although comparable means were observed in control and constipated individuals, ranges of response (especially for the meal test) were much wider in constipated patients than in control subjects. index) was larger with neostigmine than with the meal. In normal subjects, meal responses are, therefore, more homogeneous than neostigmine responses. As the increase of motility and the homogeneity of the results were better with the meal than with neostigmine, it was, therefore, concluded that meal stimulation was a better test of sigmoid motility than neostigmine stimulation.

The results of the five basal motility studies performed after a three to five hours' fast are presented in Table 3, and compared in the same Table with the results found in the same subjects after a 18-20 hours' fast. After a short fasting period (three to five hours) all motility parameters were significantly

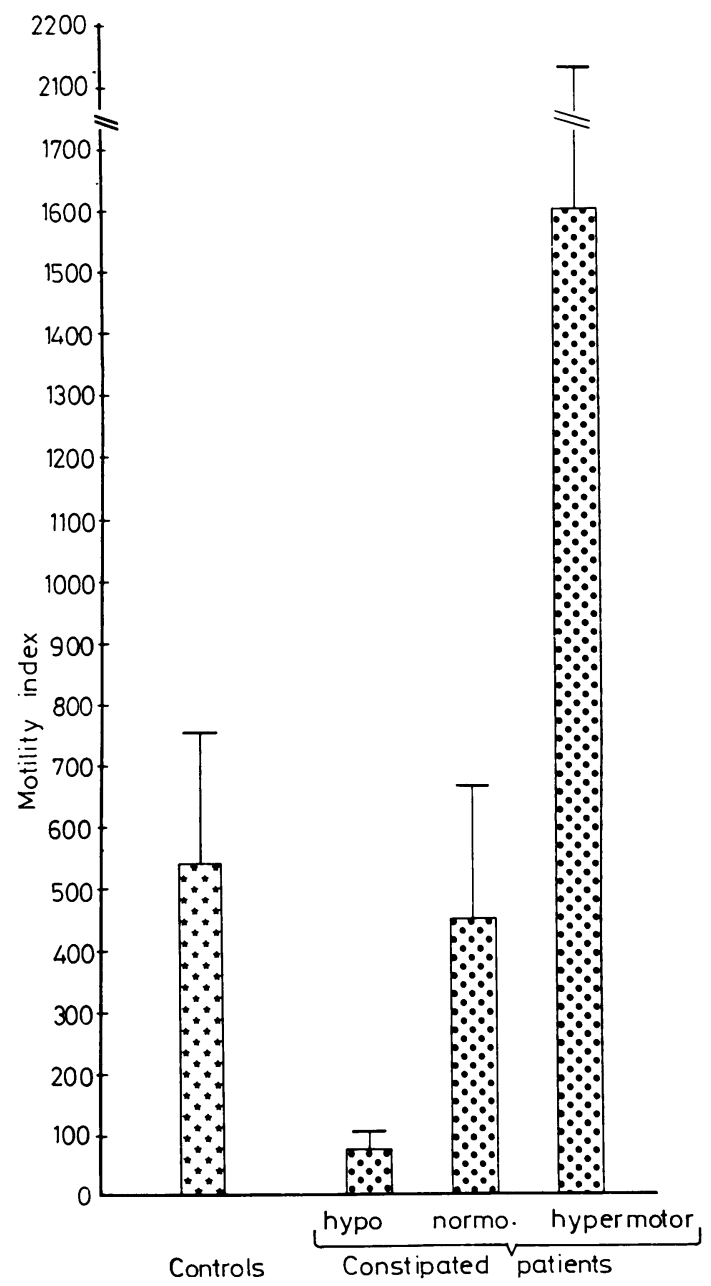

Fig. 3 Mean meal motility indexes in the three groups of constipated patients ('hypomotor', 'normomotor', and 'hypermotor') compared with that of control subjects. 
increased when compared with the motility parameters found after a fasting period of 18-20 hours $(\mathrm{P}<0.05$ for the percentage of activity, $\mathrm{P}<0.02$ for the mean amplitude of waves and the motility index).

\section{CONSTIPATED PATIENTS}

Results for the three motility parameters (mean amplitude, percentage of activity, and motility index) during the three periods of activity (basal, neostigmine response, and meal response) are presented in Table 4.

Comparison of the mean results found for constipated patients with those found for control subjects showed that, for each of the three motility parameters and for each of the three recording periods, the differences were not significant. Nevertheless (except for the mean amplitude of waves after neostigmine), the standard deviations of these means in constipated patients were larger than those found in control subjects, the standard deviation being especially large in the case of the motility index. The mean responses in our series of constipated patients therefore do not differ significantly from those of control subjects, but the distribution of the responses (especially for the motility indexes) is much larger (Fig. 2).

As the normal range was defined as the mean \pm 2 SD of values found in the controls, and as the study of control subjects demonstrated that the meal response was the best test of sigmoid motility, the constipated patients were segregated into three groups according to their meal response motility index (Fig. 3). A meal motility index of between 107 and 960 - that is, mean \pm 2 SD of the meal motility index found in the controls-was considered to be normal.

The first group consisted of eight patients with a meal motility index under 107 ('hypomotor' patients; $16 \%$ of the total number of patients). The mean motility index for the meal response was $72 \pm 30$; this mean was significantly different from that of the controls $(t=13.9, \quad \mathrm{P}<0.001)$. There were eight women in this group in which the mean age was $39 \pm 15.7$ years (range 15 to 63 years).

The second group consisted of 33 patients with a meal motility index of between 107 and 969 ('normomotor' patients; $68 \%$ of the total number of constipated patients). The mean motility index for the meal response was $450 \pm 214$, which was not significantly different from that found for controls $(t=1 \cdot 37)$. There were 27 females and six males in this group in which the mean age was $38 \pm 12.4$ years (range 22 to 72 years).

The third group consisted of eight patients with a meal motility index greater than 969 ('hypermotor' patients; $16 \%$ of the total number of constipated patients). The mean motility index for the meal response was $1606 \pm 527$ in this group; this mean was significantly different from that of the control subjects $(t=7.29, \mathrm{P}<0.001)$. There were five females and three males in this group in which the mean age was $43 \pm 12 \cdot 5$ years (range 30 to 63 years).

It should be emphasised that these motor groups were not clinically different.

\section{Discussion}

Three main conclusions can be drawn from the above results: (1) the basal level of activity after a 18-20 hours fast was found to be very low in both controls and constipated patients; (2) the value of neostigmine administration as a test of stimulation of sigmoid motility appears to be rather poor; (3) in the large majority of constipated patients, the sigmoid motility patterns are comparable with those found for the control subjects. Each of these points, which differ in certain ways from the conclusions of other studies, are worthy of discussion.

1 Our results at basal level, showing a mean percentage of activity of $8 \%$ in controls and of $11 \%$ in constipated patients, strongly differ from the high percentages of basal activity observed by others (Spriggs et al., 1951; Davidson et al., 1956; Connell, 1961 ; Parks and Connell, 1969; Weinrich and Andersen, 1976). Such conflicting results are probably due, firstly, to a difference in technique: some of the studies mentioned above were performed using balloons, and the amount of activity recorded depends on the nature of the sensing device. With the use of balloons, more activity is usually recorded than with open tip catheters (Connell, 1975).

A second factor which might explain the low level of basal activity that we observed is the long fasting period (18-20 hours) we imposed on all subjects. Indeed, most authors require fasting conditions much less drastic than ours. For instance, sigmoid motility studies were performed either after an overnight fast (Spriggs et al., 1951; Dinoso et al., 1973; Weinrich and Andersen, 1976), after a fasting period of two to six hours (Connell, 1961; Champion, 1973), or in subjects either fasted or fed (Davidson et al., 1956). In other studies, duration of the fast (if performed) was not mentioned (Parks and Connell, 1969; Waller and Misiewicz, 1972; Kirwan and Smith 1977). Weinrich and Andersen (1976), using a recording method and parameters similar to ours, observed, in their normal subjects at basal level, a mean percentage of activity of $19 \%$, a mean amplitude of the waves of $23.6 \mathrm{~cm} \mathrm{H}_{2} \mathrm{O}$, and a mean motility index of 597 . These values were, respectively, $8 \%, 9 \mathrm{~cm} \mathrm{H}_{2} \mathrm{O}$, and 82 in our controls. As the subjects studied by Weinrich and Andersen underwent 
only an overnight fast, it can be concluded that the long fasting period observed in our study was responsible for the low level of basal activity that we observed. Furthermore, the increased motility parameters obtained in our controls after only a three to five hour fast demonstrate that the high level of basal activity reported in the above papers was due to residual sigmoid motor activity. Consequently, to avoid such a residual motility, the various stimulating tests ought to be performed after a prolonged period of fasting.

2 As in the original study by Chaudary and Truelove (1961), we observed a significant increase of motility parameters with neostigmine stimulation; however, its effect was, on average, much less than that of a meal. Furthermore, in normal subjects, the standard deviations observed for the percentage of activity and the motility index were larger with neostigmine than with a meal-that is, neostigmine response was less homogeneous than meal response. In two control subjects, neostigmine had no effect, while, in one, the response was dramatic (with a motility index of 1032). Neostigmine response in normal subjects appears, therefore, to be highly unpredictable. It should be pointed out that, although neostigmine administration is one of the most oftenused sigmoid motility stimulation tests, results obtained with modern techniques in normal subjects are scarce in the scientific literature. Neostigmine stimulation has often been used in sigmoid motility studies in which controls were not included (Waller and Misiewicz, 1972; Champion, 1973; Kirwan and Smith, 1977). In addition, the pharmacological effect of neostigmine on colonic muscle is poorly understood (Bennett, 1975). As, in control subjects, the meal test induced a better response with more homogeneous results than the neostigmine test, and as a meal is perfectly physiological in nature, it seems apparent that the meal test is a much better tool of clinical investigation than is the neostigmine test. All these arguments strongly suggest the uselessness of the neostigmine test in routine studies of colonic motor disorders.

3 The last point worth considering is the fact that, in our study, the large majority of constipated patients $(68 \%$ of the total number) exhibited normal sigmoid motility parameters. This result completely differs from the classical finding of Connell (1961), in which an important increase in sigmoid motor activity was reported in constipated patients. Such an overactivity in constipated subjects has often been confirmed by others (Painter et al., 1965; Wangel and Deller, 1965; Waller, 1965; Waller et al., 1972; Chowdury et al., 1976). The patients in the present study were all selected according to a well-defined clinical picture (a duration of constipa- tion of over five years, laxative abuse, normal barium enema and rectoscopy, and exclusion of laxative disease as well as of constipation secondary to some other cause). On the other hand, the clinical pictures of the constipated patients in some of the above papers are insufficiently defined, and the duration of constipation, with the exception of the Wangel and Deller study, is not indicated. Furthermore, the work of Wangel and Deller mostly concerns constipation observed in the irritable colon syndrome. The fact that our 'normomotor' constipated patients differed from those in the above-mentioned studies, probably accounts for the discordant results that we observed.

Our 33 'normomotor' constipated patients call to mind the constipated patients with normal colonic transit times and rectal stasis observed by Hinton and Lennard-Jones (1968) in their pellet study. It is very likely that, in such 'normomotor' patients, a study of the viscoelastic properties of the rectal wall (Arhan et al., 1978) or a study of rectoanal manometric parameters (Meunier et al., 1979) would be more likely to demonstrate abnormalities. On the other hand, the eight 'hypermotor' constipated patients that we observed fit the sigmoid motor patterns first described by Connell (1961). These cases of sigmoid over-segmentation are probably cases of the irritable bowel syndrome, which is characterised by colonic overactivity (Chaudary and Truelove, 1961). For the few constipated 'hypomotor' patients observed in this study, the hypothesis of ganglionic cell lesions, due to laxative abuse, may be proposed according to the finding of Smith (1968). In these 'hypomotor' patients, as in all the other constipated patients in this study, there was evidence of prolonged and daily use of laxatives. The effect of laxatives on the ganglionic cells, however, might differ considerably from one subject to another, thus explaining why colonic hypomotility was not regularly observed in these patients.

We are grateful to Dr Y. Minaire who gave us much helpful advice. This work was done with the help of a grant from the: Faculty of Medicine Lyon Nord and the material support of INSERM U. 45.

\section{References}

Arhan, P., Devroede, G., Danis, K., Dornic, C., Faverdin, C., Persoz, B., and Pellerin, D. (1978). Viscoelastic properties of the rectal wall in Hirschprung's disease. Journal of Clinical Investigation, 62, 82-87.

Bennett, A. (1975). Pharmacology of colonic muscle. Gut, 16, 307-311.

Champion, P. (1973). Some cases of the irritable bowel syndrome studied by intraluminal pressure recordings. Digestion, 9, 21-29.

Chaudary, N. A., and Truelove, S. C. (1961). Human 
colonic motility: a comparative study of normal subjects, patients with ulcerative colitis, and patients with the irritable colon syndrome. II. The effect of prostigmin. Gastroenterology, 40, 18-26.

Chowdury, A. R., Dinoso, V. P., and Lorber, S. H. (1976). Characterization of a hyperactive segment at the rectosigmoid junction. Gastroenterology, 71, 584-588.

Connell, A. M. (1961). The motility of the pelvic colon. I. Motility in normals and in patients with asymptomatic duodenal ulcer. Gut, 2, 175-186.

Connell, A. M. (1962). The motility of the pelvic colon. II. Paradoxical motility in diarrhoea and constipation. Gut, 3, 342-348.

Connell, A. M. (1975). Applied physiology of the colon: factors relevant to diverticular disease. Clinics in Gastroenterology, 4, 23-36.

Davidson, M., Sleisenger, M. H., Almy, T. P., and Levine, S. Z. (1956). Studies of distal colonic motility in children. I. Non-propulsive patterns in normal children. Pediatrics, 17, 807-819.

Dinoso, V. P., Jr., Meshkinpour, H., Lorber, S. H., Gutierrez, J. G., and Chey, W. Y. (1973). Motor responses of the sigmoid colon and rectum to exogenous cholecystokinin and secretin. Gastroenterology, 65, 438-444.

Hinton, J. M., and Lennard-Jones, J. E. (1968). Constipation: definition and classification. Postgraduate Medical Journal, 44, 720-723.

Kirwan, W. O., and Smith, A. N. (1977). Colonic propulsion in diverticular disease, idiopathic constipation, and the irritable colon syndrome. Scandinavian Journal of Gastroenterology, 12, 331-335.

Meunier, P., Maréchal, J. M., and Jaubert de Beaujeu, M. (1979). Rectoanal pressures and rectal sensitivity studies in childhood chronic constipation. Gastro- enterology, 77, 330-336.

Meunier, P., Rochas, A., and Lambert, R. (1978). Sigmoid motility in constipation. Gastroenterology, 74, 1136 (abstract).

Painter, N. S., Truelove, S. C., Ardran, G. M., and Tuckey, M. (1965). Segmentation and the localization of intraluminal pressures in the human colon, with special reference to the pathogenesis of colonic diverticula. Gastroenterology, 49, 169-177.

Parks, T. G., and Connell, A. M. (1969). Motility studies in diverticular disease of the colon. Gut, 10, 534-542.

Smith, B. (1968). Effect of irritant purgatives on the myenteric plexus in man and the mouse. Gut, 9, 139-143.

Spriggs, E. A., Code, C. F., Bargen, J. A., Curtiss, R. K., and Hightower, N. C., Jr (1951). Motility of the pelvic colon and rectum of normal persons and patients with ulcerative colitis. Gastroenterology, 19 , 480-491.

Waller, S. L., and Misiewicz, J. J. (1972). Colonic motility in constipation or diarrhoea. Scandinavian Journal of Gastroenterology, 7, 93-96.

Waller, S. L., Misiewicz, J. J., and Kiley, N. (1972). Effect of eating on motility of the pelvic colon in constipation or diarrhoea. Gut, 13, 805-811.

Wangel, A. G., and Deller, D. J. (1965). Intestinal motility in man. III. Mechanisms of constipation and diarrhoea with particular reference to the irritable colon syndrome. Gastroenterology, 48, 69-84.

Weinreich, J., and Andersen, D. (1976). Intraluminal pressure in the sigmoid colon. 1. Method and results in normal subjects. Scandinavian Journal of Gastroenterology, 11, 577-580. 